\title{
Dukungan Suami Terhadap Penggunaan IUD Pasca Plasenta Sebagai Kontrasepsi Pasca Melahirkan
}

\author{
Wafi Nur Muslihatun ${ }^{1}$, Ana Kurniati ${ }^{2}$, Dian Maliana ${ }^{3}$, Juli Widiyanto ${ }^{4}$ \\ 1,2,3 Departement of Midwifery Poltekkes Kemenkes Yogyakarta, Jl. Tatabumi No.3 Banyuraden, \\ Gamping, Sleman \\ ${ }^{4}$ Departement of Nursing Faculty of Mathematic, Natural Sciences and Health Muhammadiyah \\ University of Riau \\ Correspondence Email : wafinuranwar@gmail.com, juliwidiyanto@umri.ac.id
}

\section{ABSTRACT}

Postplacental IUD is a post-partum contraceptive device that can be inserted directly in the first 10 minutes after the placenta is born. The low interest in post-placental IUD use is strongly influenced by husband's support. This study aims to determine the relationship between husband's support and the use of the postplacental IUD as a postdelivery family planning program. This type of research is analytic observational with a cross sectional approach. The sample of this study was 62 mothers giving birth at the Pratama Clinic Kusuma Medisca Wates taken by simple random sampling technique. The research instrument used a husband's support questionnaire. Data analysis was performed by Chi Square test. Maternal mothers who used the postplacenta IUD were more mothers who received husband's support (40.3\%) compared to mothers who did not receive husband's support. Statistical test results obtained p-value 0.000 , prevalence rate 5.26 with a confidence interval range of 0.064-0.561. Conclusion: There is a significant relationship between husband's support and the use of the postplacental IUD as a postpartum contraception.

Keywords: Husband's support, postplacenta IUD

\begin{abstract}
ABSTRAK
IUD postplasenta adalah alat kontrasepsi pasca persalinan yang dapat langsung dipasang pada 10 menit pertama setelah plasenta lahir. Rendahnya minat penggunaan IUD pasca-placenta sangat dipengaruhi oleh dukungan suami. Penelitian ini bertujuan untuk mengetahui hubungan dukungan suami dengan penggunaan IUD postplacenta sebagai KB pasca persalinan. Jenis penelitian ini adalah observasional analitik dengan pendekatan cross sectional. Sampel penelitian ini adalah 62 ibu bersalin di Klinik Pratama Kusuma Medisca Wates diambil dengan teknik simple random sampling. Instrumen penelitian menggunakan angket dukungan suami. Analisis data dilakukan dengan uji Chi Square. Ibu bersalin yang menggunakan IUD postplacenta lebih banyak pada ibu yang mendapatkan dukungan suami (40,3\%) dibandingkan dengan ibu yang tidak mendapatkan dukungan suami. Hasil uji statistik diperoleh p-value 0,000, tingkat prevalensi 5,26 dengan rentang interval kepercayaan 0,064-0,561. Kesimpulan: Ada hubungan signifikan antara dukungan suami dengan penggunaan IUD postplacenta sebagai kontrasepsi pasca persalinan.
\end{abstract}

Kata Kunci: Dukungan suami, IUD postplacenta

Received: November 2021, Accepted : November 2021 - Jurnal Photon Vol.12 No.1 DOI : https://doi.org/10.37859/jp.v12i1.3363 PHOTON is licensed under a Creative Commons Attribution-ShareAlike 4.0 International License 


\section{http://ejurnal.umri.ac.id/index.php/}

\section{Introduction}

Program Keluarga Berencana (KB) pasca persalinan merupakan salah satu program KB yang digalakkan oleh pemerintah. Penerapan KB pasca persalinan sangat penting mengingat kembalinya kesuburan pada ibu setelah melahirkan tidak dapat diketahui secara pasti. Penting untuk menggunakan kontrasepsi seawal mungkin setelah persalinan, dan KB pasca persalinan yang dapat langsung dipasang dalam 10 menit pertama setelah plasenta dilahirkan adalah Intra Uterine Device (IUD). (B et al., 2019; Mujiati, 2013)

IUD merupakan salah satu Metode Kontrasepsi Jangka Panjang (MKJP) selain Implant, Metode Operatif Wanita (MOW) dan Metode Operatif Pria (MOP). MKJP dinilai lebih menguntungkan dari segi program maupun pengguna, disamping mempercepat penurunan Total Fertility Rate (TFR). Penggunaan kontrasepsi MKJP juga lebih efisien karena bisa digunakan dalam jangka waktu lama yaitu 3-8 tahun. (BKKBN et al., 2014; Hartanto, 2004) Pemakaian IUD pasca persalinan dinilai aman, reversible, efisien, tidak menimbulkan efek sistemik, dan dapat digunakan oleh semua wanita di semua usia reproduksi selama wanita tersebut tidak memiliki kontraindikasi dengan IUD.(Diallo et al., 2019; Sridevi \& Thilagam, 2019) Cakupan peserta KB pasca persalinan di Indonesia menurut data provinsi tahun 2019 baru mencapai 34,3\% dengan jenis kontrasepsi suntik yang terbanyak yaitu 63,7\%, diikuti pil 17,4\%, IUD 7,5\%, Implant 7,3\%, kondom 4,1\%, MOW 1,8\%, dan MOP 0,2\%. KB pasca persalinan tertinggi terdapat di Provinsi Lampung yaitu sebesar 76,8\% dan yang terendah di Jawa Tengah sebesar $0,1 \%$, dan ada dua provinsi yang belum melaporkan cakupan KB pasca persalinan yaitu Provinsi DI Yogyakarta dan Sulawesi Utara.(Kemenkes, 2020) Proporsi terbesar waktu penerimaan layanan KB pertama kali setelah melahirkan berdasarkan hasil Riskesdas tahun 2018 yakni $\geq 42$ hari setelah bersalin sebesar 67,5\%, < 42 hari masa nifas sebesar 20\%, bersamaan dengan proses persalinan 7,3\%, dan setelah persalinan selesai di fasilitas pelayan kesehatan 5,2\%. Kontrasepsi suntik Depo Medroksi Progesterone Acetat (DMPA) 42,4\% masih menjadi andalan diikuti IUD 6,6\%, Implant 4,7\%, pil 8,5\%, suntikan KB 1 bulan 6,1\%, dan kondom 1,1\%.(Kemenkes, 2019). Rendahnya minat IUD postplacenta dipengaruhi oleh persepsi individu, yang dipengaruhi beberapa faktor pemodifikasi antara lain: usia, pendidikan, pengetahuan, jumlah anak, paparan sumber informasi, kondisi ekonomi, serta dukungan suami.(Notoatmodjo, 2015).

Dukungan suami merupakan salah satu variabel sosial budaya yang sangat berpengaruh terhadap pemakaian alat kontrasepsi bagi kaum wanita sebagai istri, terutama saat pemilihan KB pasca

Received: November 2021, Accepted : November 2021 - Jurnal Photon Vol.12 No.1 DOI : https://doi.org/10.37859/jp.v12i1.3363

PHOTON is licensed under a Creative Commons Attribution-ShareAlike 4.0 International License 


\section{http://ejurnal.umri.ac.id/index.php/}

persalinan. Dukungan penuh yang diberikan oleh suami terhadap pengunaan KB dapat membuat istri merasa tenang dan aman menjadi peserta KB.(Faridah, 2014) Tujuan penelitian ini adalah untuk mengetahui hubungan dukungan suami dengan penggunaan IUD postplacenta sebagai kontrasepsi pasca persalinan.

\section{The Methods}

Penelitian ini adalah penelitian analitik observasional dengan rancangan cross sectional. Populasi penelitian adalah semua ibu bersalin di Klinik Pratama Kusuma Medisca Wates Kulon Progo Yogyakarta. Jumlah sampel dalam penelitian ini sebanyak 62, diambil dengan teknik Simple Random Sampling. Kriteria inklusi sampel kasus bersedia menjadi responden, rekam medik lengkap dan tinggal bersama suami dalam satu atap (suami tidak bekerja di luar kota). Kriteria ekskusi sampel kasus ibu yang mengganti metode kontrasepsi dalam waktu 4 bulan setelah pemasangan IUD postplacenta. Penelitian dilakukan pada bulan Oktober 2020 sampai Juli 2021. Instrumen penelitian ini adalah kuesioner demografi yang menanyakan secara umum identitas responden dan kuesioner dukungan suami.(Risnawati, 2019) Proses pengambilan data penelitian dilakukan dengan mendatangi responden door to door dengan tetap menerapkan protokol kesehatan mengingat penelitian dilakukan dalam masa tanggap darurat Covid19. Hasil penelitian dianalisis dengan uji Chi Square serta perhitungan risiko relatif yang digambarkan dengan angka rasio prevalensi (Prevalensi Rate).

\section{Result and Discussion}

Dari 62 responden yang diteliti, sebagian besar responden berada pada rentang usia 20-30 tahun yakni sebanyak 43 responden $(69,4 \%)$ dan 19 responden lainnya $(30,6 \%)$ berusia $>30$ tahun. Pendidikan responden mayoritas lulusan pendidikan menengah atas (SMA) yakni sebanyak 48 responden $(77,4 \%)$, sembilan responden merupakan lulusan perguruan tinggi $(14,5 \%)$, dan lima responden $(8,1 \%)$ merupakan lulusan SMP. Mayoritas responden tidak bekerja sebanyak 35 responden (56,5\%) dan 27 responden $(43,5 \%)$ bekerja sebagai karyawan swasta. Responden mayoritas memiliki 1-2 orang anak yakni sebanyak 48 responden $(77,4 \%)$, dan 14 responden lainnya $(22,6 \%)$ memiliki $>2$ orang anak.

Received: November 2021, Accepted : November 2021 - Jurnal Photon Vol.12 No.1 DOI : https://doi.org/10.37859/jp.v12i1.3363 PHOTON is licensed under a Creative Commons Attribution-ShareAlike 4.0 International License 


\section{http://ejurnal.umri.ac.id/index.php/}

Tabel 1. Karakteristik Responden

\begin{tabular}{lcc}
\hline \multicolumn{1}{c}{ Karakteristik } & Frekuensi & \% \\
\hline Usia & & \\
$>$ 30 tahun & 19 & 30,6 \\
20-30 tahun & 43 & 69,4 \\
$<20$ tahun & 0 & 0 \\
\hline Pendidikan & & \\
Pendidikan Tinggi (Akademi, PT) & 9 & 14,5 \\
Pendidikan Menengah (SMA) & 48 & 77,4 \\
Pendidikan Dasar (SD-SMP) & 5 & 8,1 \\
\hline & & \\
Status Pekerjaan & 35 & 56,5 \\
Tidak Bekerja (IRT) & 27 & 43,5 \\
Bekerja & & \\
Jumlah Anak Hidup & 48 & 77,4 \\
1-2 anak hidup & 14 & 22,6 \\
$>2$ anak hidup & 62 & 100 \\
\hline Jumlah & & \\
\hline
\end{tabular}

Tabel 2. Hasil Analisis Bivariat Hubungan Dukungan Suami Dengan Penggunaan IUD Postplacenta Sebagai KB Pasca Persalinan

\begin{tabular}{|c|c|c|c|c|c|c|c|c|c|c|}
\hline \multirow{3}{*}{ Dukungan Suami } & \multicolumn{4}{|c|}{ KB Pasca Persalinan } & \multicolumn{2}{|c|}{ Jumlah } & \multirow{3}{*}{$\begin{array}{c}p \\
\text { value }\end{array}$} & \multirow{3}{*}{$P R$} & \multirow{2}{*}{\multicolumn{2}{|c|}{ 95\% C.I. }} \\
\hline & \multicolumn{2}{|c|}{ IUD } & \multicolumn{2}{|c|}{ Non IUD } & \multirow{2}{*}{$\mathrm{N}$} & \multirow{2}{*}{$\%$} & & & & \\
\hline & $\mathrm{n}$ & $\%$ & $\mathrm{n}$ & $\%$ & & & & & Lower & $U p_{l}$ \\
\hline Mendukung & 25 & 65.8 & 13 & 34.2 & 38 & 100 & 0.000 & 5,26 & 0,064 & 0 \\
\hline Tidak Mendukung & 3 & 12.5 & 21 & 87.5 & 24 & 100 & & & & \\
\hline Jumlah & 28 & 45.2 & 34 & 54.8 & 62 & 100 & & & & \\
\hline
\end{tabular}

Tabel 2 memperlihatkan bahwa ibu bersalin menggunakan IUD postplacenta lebih banyak pada ibu yang mendapatkan dukungan dari suaminya yakni sebesar $65.8 \%$ dibandingkan dengan ibu yang tidak mendapatkan dukungan dari suaminya (12.5\%). ibu bersalin tidak menggunakan IUD postplacenta lebih banyak pada ibu yang tidak mendapatkan dukungan dari suaminya yakni sebesar $87.5 \%$

Received: November 2021, Accepted : November 2021 - Jurnal Photon Vol.12 No.1 DOI : https://doi.org/10.37859/jp.v12i1.3363 PHOTON is licensed under a Creative Commons Attribution-ShareAlike 4.0 International License 


\section{http://ejurnal.umri.ac.id/index.php/}

dibandingkan dengan ibu yang mendapatkan dukungan dari suaminya (34.2\%). Hasil uji statistik didapatkan $p$-value $0,000 \leq \alpha=0,05$, dengan prevalensi rate sebesar 5,26.

Tabel 3. Komponen Dukungan Suami pada Penggunaan IUD Postplacenta sebagai Kontrasepsi Pascapersalinan

\begin{tabular}{|c|c|c|c|c|c|c|c|}
\hline \multirow{3}{*}{ Dukungan Suami } & \multicolumn{2}{|c|}{ KB Pasca Persalinan } & \multicolumn{2}{|c|}{ Jumlah } & \multirow{3}{*}{$p$ value } & \multirow{3}{*}{$P R$} & \multirow{2}{*}{$\begin{array}{l}95 \% \text { C.I For } \\
\text { Cohort }\end{array}$} \\
\hline & IUD & Non IUD & T & $\theta$ & & & \\
\hline & $\mathrm{n}$ & $\%$ & & & & & Lower \\
\hline
\end{tabular}

\section{Dukungan}

Informasional

\begin{tabular}{lrrrrrrrrrr} 
Mendukung & 11 & 50 & 11 & 50 & 22 & 100 & 0,763 & 1.17 & 0.489 & 1,476 \\
Tidak Mendukung & 17 & 42.5 & 23 & 57.5 & 40 & 100 & & & & \\
\hline Dukungan Emosional & & & & & & & & & & \\
\hline Mendukung & 25 & 50 & 25 & 50 & 50 & 100 & 0,215 & 2 & 0,181 & 1,384 \\
Tidak Mendukung & 3 & 25 & 9 & 75 & 12 & 100 & & & & \\
\hline Dukungan & & & & & & & & & & \\
Instrumental & 23 & 95.8 & 1 & 4.2 & 24 & 100 & 0,000 & 7,33 & 0,060 & 0,312 \\
Mendukung & 5 & 13.2 & 33 & 86.8 & 38 & 100 & & & & \\
Tidak Mendukung & & & & & & & & & & \\
Dukungan Penilaian & 20 & 100 & 0 & 0,0 & 20 & 100 & 0,000 & 5,26 & 0,102 & 0,355 \\
Mendukung & 8 & 19 & 34 & 81 & 42 & 100 & & & & \\
Tidak Mendukung & 28 & 45.2 & 34 & 54.8 & 62 & 100 & & & & \\
\hline Jumlah & & & & & & & & & & \\
\hline
\end{tabular}

Tabel 3 menunjukkan hubungan aspek komponen dukungan suami yakni dukungan informasional, dukungan emosional, dukungan instrumental dan dukungan penilaian dengan penggunaan IUD postplacenta sebagai kontrasepsi pasca persalinan. Tabel 3 menunjukkan hubungan dukungan instrumental dan dukungan penilaian dari suami dengan penggunaan IUD postplacenta sebagai kontrasepsi pascapersalinan didapatkan p-value keduanya adalah 0,000 $(<0.005)$, Prevalensi Rate masing-masing sebesar 7,33 (CI 95\% adalah 0.060-0.312) dan 5,26 (CI 95\% adalah 0.102-0.355).

Hasil penelitian ini sejalan dengan penelitian yang dilakukan di Rwanda dan Ethiopia Utara yang menyatakan bahwa persetujuan pasangan atau suami mempengaruhi penerimaan isteri dalam penggunaan IUD postplacenta dan kontrasepsi modern secara umumnya. Penelitian Kanakuze yang dilakukan di Rwanda menyatakan bahwa ibu yang menerima persetujuan pasangan lebih cenderung

Received: November 2021, Accepted : November 2021 - Jurnal Photon Vol.12 No.1 DOI : https://doi.org/10.37859/jp.v12i1.3363 PHOTON is licensed under a Creative Commons Attribution-ShareAlike 4.0 International License 


\section{http://ejurnal.umri.ac.id/index.php/}

menggunakan IUD postplacenta dibandingkan dengan ibu yang tidak mendapatkan persetujuan pasangannya.(Kanakuze et al., 2020) Penelitian di wilayah Tigray, kota Aksum, utara Ethiopia juga menyatakan hal yang sama bahwa penggunaan kontrasepsi modern pasca persalinan dengan melanjutkan hubungan seksual dan persetujuan suami mengenai keluarga berencana.(Abraha et al., 2018) Penelitian ini juga sejalan dengan penelitian yang dilakukan oleh Laily Qamariah di Puskesmas Jetis Yogyakarta tahun 2017. Hasil penelitian Qamariah didapatkan dari 26 responden yang tidak mendapatkan dukungan suami, semuanya (100\%) tidak menggunakan KB IUD postplacenta. Empat responden yang mendapatkan dukungan suami tiga (75\%) menggunakan KB IUD postplacenta. Hal ini menunjukkan bahwa dukungan suami merupakan salah faktor yang mempengaruhi penggunaan IUD postplacenta (Qomariah, 2017).

Hal berbeda diungkapakan oleh Batubara dan Utami, yang menyatakan bahwa suami tidak turut campur mengenai kontrasepsi yang digunakan oleh istri. Suami banyak tidak mendukung karena beranggapan bahwa kontrasepsi adalah urusan istri padahal dukungan suami sangat berpengaruh besar terhadap penentu penggunaan IUD postplacenta.(Batubara \& Utami, 2019) Hal yang sama juga diungkapkan oleh Da Costa, Ingabire, Sinabamenye, dan kawan-kawan yang menyatakan bahwa dukungan pasangan tidak banyak berpengaruh dalam keputusan menggunakan IUD postplacenta.(Da Costa et al., 2019). Pada hubungan aspek komponen dukungan suami didapatkan hasil bahwa sedikit responden yang memiliki suami yang berpengaruh dalam keputusan ber KB. Responden yang menggunakan IUD postplacenta sedikit lebih banyak (50\%) pada responden yang mendapatkan dukungan informasional dari suami. Aspek dukungan informasional suami menunjukkan tidak terdapat hubungan bermakna dengan penggunaan IUD postplacenta dengan $p$-value 0,763 $>\alpha=0,05$ dan prevalansi rate sebesar 1,17 dengan rentang interval kepercayaan 0,489-1,476, walaupun $\mathrm{PR}>1$, namun rentang interval kepercayaan melewati angka 1 , menjadikan variabel dukungan informasional bukan merupakan faktor resiko penggunaan IUD postplacenta sebagai KB pasca persalinan.

Minimnya dukungan suami sebagai edukator informasional terhadap penggunaan IUD postplacenta sebagai KB pasca persalinan menjadi salah satu penyebab keengganan ibu menggunakan kontrasepsi IUD. Hal ini sesuai dengan teori yang menyatakan bahwa suami sangat perlu meningkatkan pengetahuannya tentang kontrasepsi pasca persalinan yang dapat digunakan, terutama IUD postplacenta. Informasi dan pengetahuan mengenai kontrasepsi pasca persalinan dapat diperoleh suami dengan cara turut serta konseling KB pasca persalinan.(Fithriany, 2011) Ibu bersalin yang menggunakan IUD postplacenta sebagai KB pasca persalinan lebih banyak pada ibu yang

Received: November 2021, Accepted : November 2021 - Jurnal Photon Vol.12 No.1 DOI : https://doi.org/10.37859/jp.v12i1.3363

PHOTON is licensed under a Creative Commons Attribution-ShareAlike 4.0 International License 


\section{http://ejurnal.umri.ac.id/index.php/}

mendapatkan dukungan emosional dari suaminya yakni sebesar 50\%. Hasil analisis didapatkan p-value $0,215>\alpha=0,05$ yang bermakna bahwa tidak ada hubungan antara dukungan emosional dengan penggunaan IUD postplacenta sebagai KB pasca persalinan. Prevalensi rate sebesar 2 dengan rentang interval 0,181-1,384. maka walaupun PR > 1, namun rentang interval kepercayaan yang melewati angka 1, menjadikan variabel dukungan emosional bukan merupakan faktor resiko penggunaan IUD postplacenta sebagai KB pasca persalinan.

Dukungan instrumental merupakan bentuk bantuan langsung berupa tenaga, dana, dan waktu. Dukungan instrumental merupakan bentuk tanggung jawab "fisik" suami sebagai kepala keluarga. Mayoritas ibu bersalin yang menggunakan IUD postplacenta lebih banyak pada ibu yang mendapatkan dukungan istrumental dari suaminya yakni sebesar $95.8 \%$. Hasil analisis didapatkan $p$-value $0,000 \leq 0$ $=0,05$ dapat disimpulkan bahwa ada hubungan yang signifikan antara dukungan instrumental suami dengan penggunaan IUD postplacenta sebagai KB pasca persalinan. Prevalensi rate sebesar 7,33 dengan rentang interval 0,060-0,312, maka PR > 1 dan rentang interval kepercayaan tidak melewati angka 1, berarti variabel dukungan instrumental suami merupakan faktor resiko penggunaan IUD postplacenta sebagai KB pasca persalinan.

Dukungan penilaian suami dengan penggunaan IUD postplacenta sebagai KB pasca persalinan memperlihatkan bahwa ibu bersalin yang memilih menggunakan IUD postplacenta lebih banyak pada ibu yang mendapatkan dukungan penilaian dari suaminya yakni sebesar $100 \%$. Hasil analisis didapatkan $p$-value $0,000 \leq \alpha=0,05$ dapat disimpulkan bahwa ada hubungan yang signifikan antara dukungan penilaian dengan penggunaan IUD postplacenta sebagai KB pasca persalinan. Prevalensi rate sebesar 5,26 dengan rentang interval 0,102-0,355. Nilai PR > 1 dan rentang interval kepercayaan tidak melewati angka 1 , berarti variabel dukungan penilaian suami merupakan faktor resiko penggunaan IUD postplacenta sebagai KB pasca persalinan.

Pandangan serta dukungan suami tentang KB akan sangat berpengaruh terhadap keputusan di dalam keluarga untuk menggunakan alat atau cara KB tertentu.(Setiawati et al., 2017) Suami menjadi individu yang berperan sebagai dukungan sosial bagi istri dalam pemilihan alat kontrasepsi yang dipilih. Penelitian Anguzu menyebutkan bahwa persepsi terhadap keputusan pasangan secara positif mempengaruhi pemilihan kontrasepsi.(Anguzu et al., 2014) Hasil penelitian tersebut sesuai dengan hasil penelitian ini yang menunjukkan pengaruh dukungan suami terhadap pemilihan kontrasepsi IUD. Dukungan suami sangat diperlukan karena dapat memberikan motivasi dan kenyamanan dalam memilih menggunakan alat kontrasepsi atau bahkan menghentikannya.

Received: November 2021, Accepted : November 2021 - Jurnal Photon Vol.12 No.1 DOI : https://doi.org/10.37859/jp.v12i1.3363 PHOTON is licensed under a Creative Commons Attribution-ShareAlike 4.0 International License 


\section{http://ejurnal.umri.ac.id/index.php/}

\section{Conclusion}

Ada hubungan dukungan suami dengan penggunaan IUD postplacenta sebagai kontrasepsi pascapersalinan. Ibu bersalin yang mendapatkan dukungan dari suami berpeluang 5,26 kali lebih besar memilih menggunakan IUD postplacenta sebagai KB pasca persalinan. Diharapkan kepada bidan dan tenaga kesehatan untuk meningkatkan edukasi dan dukungan suami dalam upaya menaikkan penggunaan IUD postplacenta sebagai kontrasepsi pascapersalinan.

\section{Acknowledgement}

Penulis mengucapkan terima kasih kepada Ketua Jurusan Kebidanan dan Direktur Poltekkes Kemenkes Yogyakarta yang telah memberikan kesempatan sehingga hasil penelitian ini dapat dipublikasikan.

\section{References}

Abraha, T. ., Belay, H. ., \& Welay, G. . (2018). Intentions on Contraception Use and Its Assosiated Factors Among Postpartum Women in Aksum Town, Tigray Region, Northern Ethiopia: A Community-based Cross Sectional Study. BMC Reproductive Health, 15(188).

Anguzu, R., Tweheyo, R., Sekandi, J. ., Zalwango, V., Muhumuza, C., Tusiime, S., \& Serwada, D. (2014). Knowledge and attitudes towards use of long acting reversible contraceptives among women of reproductive age in Lubaga division, Kampala district, Uganda. BMC Research Notes, $7(153)$.

B, R., Shivakumar, \& Paprikar. (2019). To Study the Safety and Efficacy of Post-Partum Intra-Uterine Contraceptive Device. International Journal of Research \& Review, 6(10), 2237-2454.

Batubara, S., \& Utami, R. (2019). Faktor-Faktor Yang Berhubungan Dengan Kesediaan Ibu Bersalin Untuk Pemasangan IUD Post Plasenta. Jurnal Penelitian Kebidanan Dan Kespro, 1(2).

BKKBN, RI, K., POGI, IDI, IBI, PKBI, \& PKMI. (2014). Buku Panduan Praktis Pelayanan Kontrasepsi. PT Bina Pustaka Sarwono Prawirohardjo.

Da Costa, V., Ingabire, R., Sinabamenye, R., Karita, E., Umotoni, V., Hoagland, A., Allen, S., Mork, E., Parker, R., Mukamunyango, J., Haddad, L., Nyombanyire, J., \& Wall, K. . (2019). An Exploratory Analysis of Factors Associated with Interest in Postpartum Intra Uterine Device Uptake Among Pregnant Women and Couples in Kagali, Rwanda. Clinical Medicine Insight: Reproductive Health, 13(1).

Diallo, M., Daff, H. M. ., Diouf, A. ., Niass, A., Toure, Y., Fall, K., \& Al, E. (2019). Intrauterine Device in the Immediate Postpartum: Study Comparing Insertion after Cesarean Section and Vaginal Delivery. Open Journal of Obstetrics and Gynecology, 9, 1510-1518.

Faridah. (2014). Faktor Yang Mempengaruhi KB MKJP. Ejournal.Unair.Ac.Id.

Received: November 2021, Accepted : November 2021 - Jurnal Photon Vol.12 No.1

DOI : https://doi.org/10.37859/jp.v12i1.3363

PHOTON is licensed under a Creative Commons Attribution-ShareAlike 4.0 International 


\section{http://ejurnal.umri.ac.id/index.php/}

Fithriany. (2011). Pengaruh Karakteristik Ibu dan Dukungan Suami Terhadap Pemeriksaan Kehamilan di Kecamatan Kuta Cot Glie Kabupaten Aceh Besar. Universitas Sumatera Utara.

Hartanto. (2004). Keluarga Berencana dan Kontrasepsi. Sinar Harapan.

Kanakuze, C., Dan, K., Musabirema, P., Pascal, N., \& Mbalinda, S. (2020). Factors Assosiated With The Uptake of Immediate Postpartum Intrauterine Contraceptive Devices (PPIUD) In Rwanda: A Mixed Methods Study. Research Square.

Kemenkes, R. (2019). Laporan Nasional RISKESDAS 2018. Kementerian Kesehatan RI.

Kemenkes, R. (2020). Profil Kesehatan Indonesia Tahun 2019. Kementerian Kesehatan RI.

Mujiati, I. (2013). Pelayanan KB Pasca Persalinan dalam Upaya Mendukung Percepatan Penurunan Angka Kematian Ibu. Buletin Jendela Data Dan Informasi Kesehatan., 1, 11-16.

Notoatmodjo, S. (2015). Pendidikan dan Perilaku Kesehatan. Rieneka Cipta.

Qomariah, L. (2017). Hubungan Dukungan Suami dan Tingkat Pengetahuan Dengan Penggunaan KB IUD Postplacenta Di Puskesmas Jetis Yogyakarta. Universitas 'Aisyiyah Yogyakarta.

Risnawati, S. (2019). Faktor Yang Mempengaruhi Minat Ibu Menggunakan KB Intra Uterine Device (IUD) di Puskesmas Binjai Estate Tahun 2019. Institut Kesehatan Helvatia Medan.

Setiawati, E., Handayani Oktia, W. ., \& Kuswardinah, A. (2017). Pemilihan Kontrasepsi Berdasarkan Efek Samping Pada Dua Kelompok Usia Reproduksi. Unnes Journal of Public Health, 6(3).

Sridevi, R., \& Thilagam. (2019). Acceptability and Uptake of Immediate Postplacental Insertion of Intrauterine Contraceptive Device (Copper-T)- A Cross Sectional Study. PARIPE2019X INDIAN JOURNAL OF RESEARCH, 8(11).

Received: November 2021, Accepted : November 2021 - Jurnal Photon Vol.12 No.1 DOI : https://doi.org/10.37859/jp.v12i1.3363

PHOTON is licensed under a Creative Commons Attribution-ShareAlike 4.0 International

\section{License}

